\title{
The importance of sediment in sea-level change
}

Ken L. Ferrier ${ }^{1}$, W. van der Wal' ${ }^{2}$ G.A. Ruetenik ${ }^{1}$ and P. Stocchi ${ }^{3}$

\begin{abstract}
The movement of sediment across Earth's surface affects sea level by deforming the solid Earth, modifying the gravity field, and displacing and absorbing water. Recent studies show that accounting for sediment redistribution is important for interpreting and predicting sea-level change.
\end{abstract}

Since the 19th century, it has been recognized that spatially variable sea-level changes result from changes in surface loading, which perturb Earth's gravity field and the elevation of the crust (Jamieson 1865; Woodward 1888). Several decades ago, this connection was formalized in a gravitationally self-consistent theory of sea-level change (Farrell and Clark 1976), which, for the first time, accounted for both solid Earth deformation and the gravitational attraction of water toward itself, thus capturing the perturbations in both the sea floor and the sea surface that accompany ice melt. This theory has since been extended to account for several processes that were not included in Farrell and Clark's classic study, including shoreline migration (Johnston 1993), Earth rotation (Milne and Mitrovica 1996), sediment redistribution (Dalca et al. 2013), and dynamic topography (Austermann and Mitrovica 2015)

To date, most applications of this theory have focused on sea-level responses to the growth and retreat of ice sheets, which produce the largest changes in surface loads over glacial-interglacial timescales. The retreat of the Laurentide ice sheet, for example, produced a rate of mass unloading $\sim 10^{2}-10^{3}$ times higher than that due to erosion in Earth's most rapidly eroding mountain ranges.

Recent work has shown that sediment erosion and deposition, like ice growth and melt, produce significant changes in Earth's crustal elevation, gravity field, and rotation axis, all of which induce changes in sea level. In this paper, we review the ways in which sediment redistribution affects sea level and demonstrate how this can improve our understanding of past sea-level change.

\section{Processes and observations of} sediment redistribution

Sea-level responses to changes in surface loading are described by the sea-level equation (Eq. 1), which describes the change in sea level from one time to another, $\triangle S L$ (Fig. 1; Dalca et al. 2013).

$$
\Delta S L=\Delta G-\Delta H-\Delta l-\Delta R
$$

Here $\Delta H$ and $\Delta /$ are changes in the thicknesses of sediment and grounded ice, respectively, and are the drivers of sea-level change. $\Delta G$ and $\Delta R$ are changes in the elevations of the sea-surface gravitational equipotential and crust, respectively, and are responses to $\Delta H$ and $\Delta /$ that depend on Earth's viscoelastic structure. Solid Earth responses to sediment redistribution over long timescales ( $>10^{5}$ years) are often determined solely from the elastic flexure of the lithosphere, while responses over shorter timescales depend on the transient viscoelastic behavior of the mantle. Gravitational responses, by contrast, are essentially instantaneous, and continue evolving during sediment redistribution.

Quantifying $\Delta H$ requires establishing the rates and patterns of sediment erosion and deposition through time and space. At the largest scale, this includes erosion by fluvial, glacial, and hillslope processes, and deposition in subaerial floodplains, marine deltas, and fans. Integrated over the globe, these fluxes of sediment are large. Rivers currently carry $18 \pm 9$ billion tons/year of sediment to the ocean (Willenbring et al. 2013), which is an order of magnitude smaller than ice-sheet mass change globally, but which can dominate changes in loading locally.

Because rates of erosion and deposition vary strongly in space, it is necessary to turn to empirical measurements to obtain realistic estimates of $\Delta H$. Erosion rates are

A

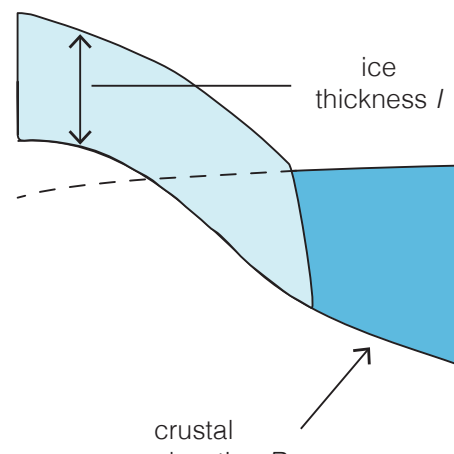

elevation $R$ sea surface equipotential $G$

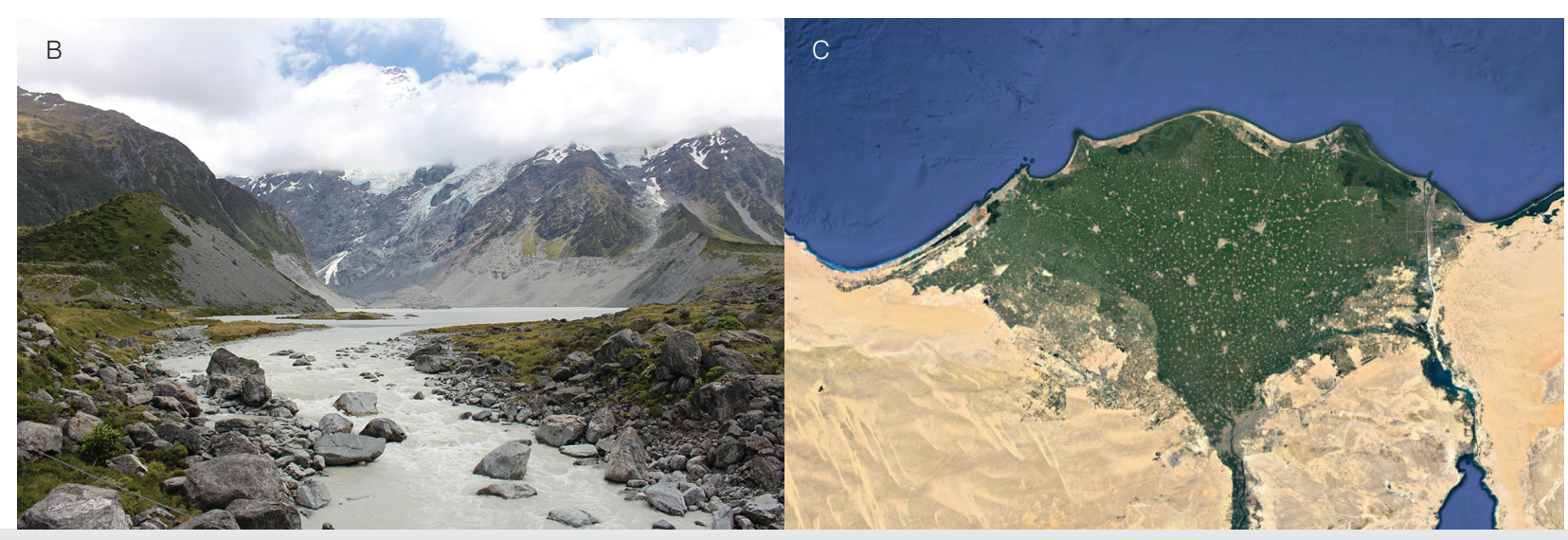

Figure 1: (A) Components in the sea-level equation (Eq. 1). The largest influences of sediment on sea-level change are in places with rapid erosion, such as rapidly uplifting mountains, e.g. (B) the New Zealand Southern Alps, or rapid deposition, e.g. (C) the Nile Delta (Google Earth 2019). 
Change in sediment thickness $\Delta H$

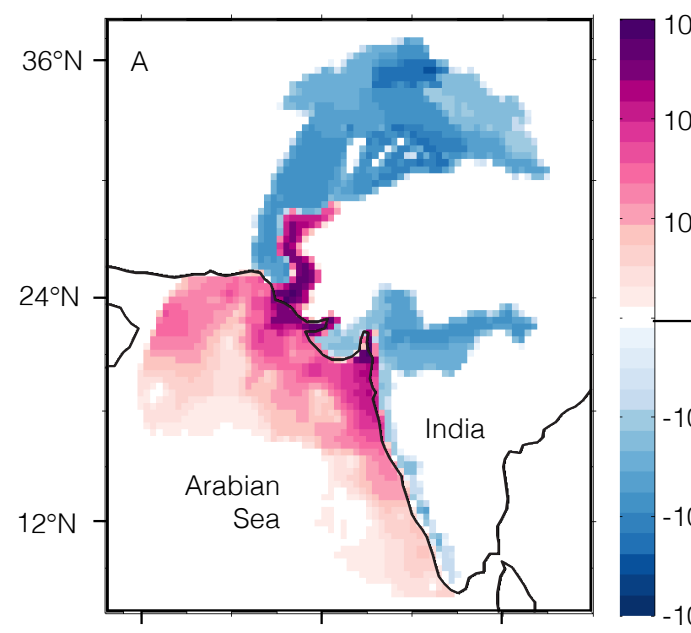

$60^{\circ} \mathrm{E}$

$70^{\circ} \mathrm{E}$

$80^{\circ} \mathrm{E}$

10

$1000 \mathrm{~m}$

100

을
$\frac{1}{0}$
0
$\frac{0}{0}$
0

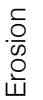

$-100$

$-1000$

Figure 2: (A) Cumulative changes in sediment thickness over a 122-kyr simulation dominated by rapid erosion in the western Himalaya and rapid deposition on the Indus delta and plain. (B) Modeled changes in sea-level $(\Delta G-\Delta R$ ) due to sediment redistribution are as large as $\sim 30 \mathrm{~m}$, far exceeding published estimates of eustatic sea-level change over this period. This highlights the importance of accounting for the effects of sediment redistribution when using paleo sea-level markers to infer past sea-level change. Modified from Ferrier et al. (2015).

routinely inferred from fluvial sediment and solute fluxes, which provide rates averaged over annual to decadal timescales, and from cosmogenic nuclide concentrations in fluvial sediment, which yield rates averaged over $\sim 10^{3}-10^{5}$ years. Deposition rates are traditionally inferred from the age and thickness of sediment cores, which typically yield rates over $\sim 10^{2}-10^{5}$ years. Recently, new approaches have been developed to infer sediment deposition rates through remotely sensed perturbations in the gravity field (Mouyen et al. 2018). Although no single method can yield a continuous record of the history of erosion and deposition, the combination of methods provides useful constraints on the history of sediment redistribution over a range of timescales.

\section{Effects of sediment redistribution and compaction on sea level and ocean water volume}

Figure 2 illustrates responses to sediment redistribution in a simulation of sea-level change driven by erosion in the Indus River basin and deposition in the Arabian Sea and the Indus plain (Ferrier et al. 2015). This produces a cumulative change in sediment thickness $(\Delta H)$ as large as hundreds of meters over the 122-kyr simulation (Fig. 2a) and a sediment flux from the Indus River of $\sim 400$ million tons/year, one of the largest fluvial sediment fluxes on Earth. This results in sea-level changes $>30 \mathrm{~m}$ near the center of the Indus delta (Fig. 2b), implying that a hypothetical paleoshoreline that formed there during the Last Interglacial would now be submerged by tens of meters.

The gravitationally self-consistent sea-level theory was recently extended (Ferrier et al. 2017) to account for two sedimentary effects that had long been recognized but not yet accounted for in the theory: the effects of sediment compaction on sediment thickness, and the effects of sedimentary water storage on global ocean water volume. Ferrier et al. (2018) applied this theory to a global sediment budget constrained by modern fluvial sediment fluxes, and showed that sedimentary water storage is capable of modifying the global volume of ocean water by the equivalent of $\sim 2 \pm 1 \mathrm{~m}$ in global mean sea level since the Last Interglacial, a significant fraction of the inferred 6-9 $\mathrm{m}$ drop in global mean sea level over this time (Kopp et al. 2009).

These sedimentary effects have important implications for interpreting past sea-level records. First, they imply that paleoshoreline elevations need to be corrected for the deforming effects of sediment, especially near locations of rapid deposition and erosion and over long time periods. Second, paleoshoreline-based inferences of past global ice volume need to properly account for changes in the volume of water stored in sediment.

\section{Conclusions}

Over the past five years, a number of studies have applied the gravitationally self-consistent sea-level theory to show that sediment redistribution can be a major driver of sea-level change. These studies have shown that sea-level responses are especially large in river systems with large sediment loads (Ferrier et al. 2015; Kuchar et al. 2018), and that sediment redistribution by other processes (e.g. subglacial erosion; van der Wal and IJpelaar 2017) can induce sea-level responses as well.

Several challenges remain. The history of sediment redistribution is poorly known in many locations due to limited measurements of paleo erosion rates, deposition rates, porosity, and density, especially for periods further in the past. In addition, lateral variations in mantle viscosity and lithospheric effective elastic thickness can strongly modulate sealevel changes, but exploring these effects is challenging due to uncertainties in Earth's rheological structure and the computational expense of modeling sea-level responses on a laterally varying Earth. Such challenges motivate continued efforts to constrain the Earth's sediment redistribution history and its three-dimensional structure, and to include erosion and deposition in coupled Earth system models that link climate forcings to sediment redistribution, glaciation, and sea-level change. Improved constraints on sediment redistribution, for example, may be useful in aiding interpretations of Gravity Recovery and Climate Experiment (GRACE) satellite data. Together, these studies highlight the rich behavior of sea-level responses to sediment redistribution, and reveal opportunities for improving our understanding of past and future sea-level change.

\section{AFFILIATIONS}

'Department of Geoscience, University of WisconsinMadison, USA

${ }^{2}$ Faculty of Civil Engineering and Geosciences, Delft University of Technology, Netherlands

${ }^{3}$ Royal Netherlands Institute for Sea Research, Texel, Netherlands

CONTACT

Ken Ferrier: kferrier@wisc.edu

REFERENCES

Austermann J, Mitrovica J (2015) Geophys J Int 203: 1909-1922

Dalca A et al. (2013) Geophys J Int 194: 45-60

Google Earth 7.3 (2019) $30.89^{\circ} \mathrm{N}, 31.09^{\circ} \mathrm{E}$, viewing elevation $350 \mathrm{~km}$. 3D map, satellite layer, viewed 1 March 2019, google.com/earth/index.html

Farrell W, Clark J (1976) Geophys J Int 46: 647-667 Ferrier Ket al. (2015) Earth Planet Sci Lett 416: 12-20 Ferrier Ket al. (2017) Geophys J Int 211: 663-672 Ferrier Ket al. (2018) Geophys Res Lett 45: 2444-2454 Jamieson T (1865) Quart J Geol Soc London 21: 161-203 Johnston P (1993) Geophys J Int 114: 615-634

Kopp R et al. (2009) Nature 462: 863-867

Kuchar J et al. (2018) J Geophys Res Solid Earth: 123 780-796

Milne GA, Mitrovica JX (1996) Geophys J Int 126: F13-F20 Mouyen M et al. (2018) Nat Commun 9: 3384 van der Wal W, IJpelaar T (2017) Solid Earth 8: 955-968 Willenbring J et al. (2013) Geology 41: 343-346 Woodward R (1888) USGS Bull 48: 87-170 